\title{
UMA PERSPECTIVA ACERCA DO REGIME MATRIMONIAL OBRIGATÓRIO DE SEPARAÇÃO DE BENS AOS MAIORES DE SETENTA ANOS
}

\section{Cristiano Colombo $^{1}$}

\section{INTROITO}

Opresente artigo tem como escopo refletir acerca do regime obrigatório de separação de bens dos maiores de setenta anos, realizando para tanto uma análise histórica dos regimes matrimoniais aplicáveis, voltandose à pesquisa da teoria estrangeira e brasileira relativa ao tema. Para tanto, tendo como ponto de partida a préhistória, buscou-se analisar o Direito da antiguidade clássica, avançando pelos povos germânicos, Idade Média, Ordenações do Reino de Portugal e respectivos alvarás, bem com os textos dos Códigos Civis Brasileiros de 1916 e 2002. Em nível nacional, fez-se a identificação da aplicação do instituto jurídico, partindo dos dispositivos de lei, analisando a jurisprudência aplicável, mormente a Súmula 377 do Supremo Tribunal Federal. A segunda parte deste estudo se volta para os princípios que devem nortear o regime de bens, passando pelo princípio do não enriquecimento sem causa e da autonomia da vontade, com incursões no Direito Comparado Francês, Italiano e Português. Por último, com base em todas as reflexões desenvolvidas, apresentar-se-á uma perspectiva acerca do tema, a fim de dar novos rumos ao tema em questão, em face das necessárias alterações legislativas.

1 Doutorando em Direito pela Universidade Federal do Rio Grande do Sul (UFRGS). Mestre em Direito pela UFRGS. Bacharel em Ciências Jurídicas e Sociais pela Pontifícia Universidade Católica do Rio Grande do Sul - PUCRS (1999) e em Ciências Contábeis pela UFRGS (2004). Especialista em Direito Tributário pelo Instituto Brasileiro de Estudos Tributários (IBET). É professor da Faculdade de Direito da Instituição Educacional São Judas Tadeu, bem como no Curso Verbo Jurídico. 


\section{DO REGIME}

\section{OBRIGATÓRIO DE} SEPARAÇÃO DE BENS AOS MAIORES DE SETENTA ANOS

\subsection{Da história da separação de bens como regime matrimonial}

\author{
O artigo 1.511 inaugura o Livro
} IV do Código Civil Brasileiro, dedicado ao Direito de Família, conceituando o instituto do casamento como “a comunhão plena de vida, com base na igualdade de direitos entre os cônjuges"2. Importa destacar que, no decorrer dos dispositivos que compõem o Livro do Direito de Família, depreendem-se comandos de ordem pessoal e patrimonial. Os ordenamentos jurídicos, ao longo da história, no intuito de disciplinar o direito de família patrimonial, desenvolveram para tanto os chamados regimes matrimo- niais de bens. Segundo Hémard³, há necessidade de organização de um regime matrimonial entre aqueles que entre si estabelecem uma comunidade de vida, a saber:

Quand deux personnes se marient, leur communauté d'existence entraîne une communauté d'intérêts. Une confusion matérielle s'opère entre leurs biens, au moins pour les meubles; des besoins communs, des charges communes, naissent de la création d'une famille nouvelle à élever. L'organisation d'un régime matrimonial apparaît naturelle, elle est même nécessaire, car partout où se manifeste une activité commune, une réunion licite de biens, il faut les soumettre à une condition spéciel. Même en absence de mariage, en cas d'union libre, on doit établir un certain régime des biens, et la jurisprudence a dû reconnaître que de la vie en commun et la confusion des

2 BRASIL. Lei $n^{\circ}$ 10.406, de 10 de janeiro de 2002, da República Federativa do Brasil. Brasília, DF. Disponível em: <http://www.planalto.gov.br/ccivil_03/LEIS/2002/ L10406compilada.htm>. Acesso em: 20 jan. 2012.

3 Tradução livre do autor: Quando duas pessoas se casam, com a comunidade de existência arrastam consigo uma comunidade de interesses. Uma confusão material se opera entre seus bens, ao menos com os móveis; as necessidades comuns, os encargos comuns, nascem da criação de uma nova família em crescimento. A organização de um regime matrimonial aparece naturalmente, ela é necessária, em todos os lugares em que se manifestam a atividade humana, uma reunião lícita de bens, é necessário submeter a uma cláusula especial. Mesmo na ausência de casamento, no caso de união livre, devese estabelecer um certo regime de bens, e a jurisprudência tem reconhecido que a vida em comum e a confusão dos bens dos concubinos derivam de uma comunhão de fato, submissa às regras de indivisão, necessitando de uma partilha e uma liquidação: estado submisso, de preferência procurado, que se revela quando do momento da separação ou da morte (HÉMARD, Joseph. Précis Élémentaire de Droit Civil. 2. ed. Paris: Librairie du Recueil Sirey, 1936, p. 4). 
biens de concubins découle une communauté de fait, soumise aux règles de l'indivision, nécessitant um partage et un liquidation: état subi, plutôt qu'état cherché, qui ne se revele guère qu'au moment de la séparation ou du décès.

Acentuou ainda Hémard ${ }^{4}$ que: “o regime matrimonial de bens tem por objetivo regrar a condição dos bens de cada cônjuge no curso do matrimônio e as relações jurídicas resultantes deles”. A partir dessa necessidade, que decorre naturalmente da união de interesses do casal, é que ao longo da história identifica-se um movimento pendular no tocante ao poder de administração dos bens, ora atribuindo-o exclusivamente a um dos consortes em detrimento do outro, ora buscando tratar com independência o patrimônio de cada cônjuge na organização de sua vida patrimonial; esta última hipótese que se amolda aos interesses e direitos contemplados no regime da separação de bens.
Ao se buscar um retour histórico, o homem, mesmo antes da escrita, já vivia em grupos organizados, em regime de colaboração e divisão de tarefas. Com o advento da palavra escrita, o registro visível dessa organização social, econômica e cultural demonstrou que instituições civis como o casamento e o poder maternal ou paternal sobre os filhos já existiam de longa ${ }^{5}$. Aubéry ${ }^{6}$ ensinou que, na antiguidade mais remota, o poder era maternal, provavelmente atribuído à glorificação da mulher em face da maternidade, é o que se transcreve:

Il est à peu établi que, dans l'antiquité la plus recullé, le sceptre domestique était dévolu à la mère. La famille aurait ainsi commencé; par la parenté maternelle. Le matriarcat ou règne de la femme aurait pris naissance dans la glorification de la matérnite.

Refere Noronha", a saber: "Segundo registra a história, quando a sociedade se organizou em tribos, a família formou-se em torno da mu-

4 "Un regime matrimonial a pour but de régler la condition des biens de chacun des époux au cours du mariage et les rapports juridiques em résultant entre eux" (Ibidem).

5 GILSSEN, John. Introdução Histórica ao Direito. 2. ed. Lisboa: Fundação Calouste Gulbenkian, 1995, p. 31.

6 Tradução livre do autor: Há pouco foi estabelecido que, na antiguidade mais remota, o cetro doméstico era devolvido à mãe. A família teria assim começado pelo parentesco maternal. O matriarcado ou reinado da mulher teria nascido em face da glorificação da maternidade” (AUBÉRY, Gaëtan. La Communauté de Biens Conjugale. Paris: Libraire Générale de Droit \& Jurisprudence, 1911, p. 20).

7 NORONHA, Carlos Silveira. Conceito e fundamentos da família e sua evolução na ordem jurídica. Revista Forense, Rio de Janeiro, v. 326, abr.mai.jun. 1994, p. 22. 
lher, admitindo-se então a poliandria e resultado, daí a forma do matriarcado". Com o passar do tempo, nas sociedades primitivas, o poder marital começa a se impor, em face de sua força física, protegendo sua esposa e família ${ }^{8}$. No transcorrer da história, o Direito da antiga Grécia desenvolveu uma concepção elevada do casamento, como se os cônjuges fossem duas metades de um todo, a saber:

On trouve dans l'Economique de Xénophon ume conception élevé du mariage et l'éloge d'une sorte de communauté universelle entre les époux. [...] Platon nous parles des époux comme de deux moitiés d'un même tout, qui auraient été déja unies dans un monde antérieur et se rejoindraient dans celui-ci9 .

Plutarco $^{10}$, acerca do tema, em sua obra "Précepts sur les mariages" declarou que: "É necessário que o marido e a mulher coloquem em comum sem distinção tudo o que possuem e que não há nada de particular para nenhum deles".

No território da Gália, antes do contato mais próximo daqueles povos denominados de bárbaros com a civilização romana, foi possível verificar que o povo "bárbaro" gaulês reunia uma evidente superioridade em termos de valores morais, no trato com sua esposa e filhos. Um dos exemplos históricos que fundamentam essa afirmação é o fato de que, após terem os maridos recebidos os dotes das esposas, os homens colocavam em comum seus próprios bens. Destarte, essa massa de bens, adição do dote com os bens do marido, formava-se um todo monetariamente avaliável, em que os frutos eram conservados e, com o falecimento de um deles, o cônjuge sobrevivente ficava com a parte dos dois e, ainda, mais os frutos havidos anteriormente ${ }^{11}$. Aubéry ${ }^{12}$ acrescenta que alguns autores identificam no

8 "Le mari devait être naturallement le protecteur de la femme et de la famille. Or, pour qu'il pût remplir ce devoir de la défense, il fallait l'investir de pouviors suffisantes. De là est née l'autorité maritale, qui a evolué à travers les ages et s'est policée peu à peu, sou s l'action des moeurs et des lois” (AUBÉRY, op. cit., p. 21).

9 Tradução livre do autor: Encontra-se na Econômica de Xénophon uma concepção elevada do casamento e o elogio de um tipo de comunidade universal entre os esposos. [...] Platão nos fala dos esposos como duas metades de um mesmo todo, que já teriam sido unidos em um mundo anterior e se encontrariam neste” (Ibidem, p. 27).

10 "Preceitos sobre o casamento" (Apud AUBERY, op. cit., p. 28).

11 AUBÉRY, Gaëtan. La Communauté de Biens Conjugale. Paris: Libraire Générale de Droit \& Jurisprudence, 1911, p. 33.

12 Tradução livre do autor: Alguns autores creem encontrar neste costume celta o gérmen da comunidade conjugal. Argumentaram neste sentido que se fundam principalmente na expressão ‘comunicam', que implica na formação de uma massa comum” (Ibidem). 
direito gaulês o germe da comunhão conjugal de bens, a saber:

Quelques auteurs ont cru trouver dans cet usage celtique le germe de la communauté conjugale. On a argumenté dans ce sens em se fondant principalement sur l'expression communicant, qui implique la formation d'une masse commune.

Com o transcorrer dos anos, aporta-se ao Direito Romano, que, nas palavras de Modestino ${ }^{13}$, extraída do Digesto (D.23,2,1), definia o casamento como nuptiae sunt coniunctio maris et feminae et consortium omnis uitae, diuini et humani iuris communicatio. A partir desse conceito, para melhor compreender o regime de bens matrimonial aplicado em Roma, há que se verificar se a celebração do casamento vinha ou não acompanhada do ato solene denominado "conuentio in manum". A "conuentio in manum" fazia com que o marido (ou seu paterfamílias) adquirisse a manus sobre a mulher. Quando o casamento não era acompanhado do ato "conuentio in manum", o contrato era sine manu, ou seja, permanecia a esposa na família de seu pai ${ }^{14}$. Aubéry ${ }^{15}$ referiu que a instituição da manus fazia cair no poder do marido ou do pai da mulher com o patrimônio presente e futuro da mulher, servia maravilhosamente ao desejo dos velhos romanos no sentido de sujeitar a mulher. $\mathrm{O}$ casamento cum manus tinha como consequência que a esposa entrasse na família do marido e a conferia os direitos de agnato, submetendo-a aos poderes do pai do marido, se o marido era ainda alieni iuris, seja ao próprio poder do marido, se ele estivesse liberado do patria potestas.

Acerca do poder do paterfamilias, Bonfante ${ }^{16}$ reforçou que o poder do paterfamilias não tem limites na lei, mas na lei da própria família:

13 “As núpcias, ou matrimônio, são a união do homem e da mulher, a qual encerra comunhão indivisível de vida.” (ALVES, José Carlos Moreira. Direito Romano, Rio de Janeiro: Forense, 2008, p. 637).

14 Ibidem, p. 644.

15 AUBÉRY, op. cit., 1911.

16 Tradução livre do autor: O Estado, não que respeite a moral, respeita o direito da família; o Estado nesse corpo autônomo não penetrou jamais completamente, salvo para as funções mais essenciais à assistência, à milícia e à participação da soberania política, na sua esfera. Mas reduzida a questão a termo, o contraste desaparece. Não é que a civitas queira ilimitada patria potesta, mas somente a patria potestas não tem limites na lei, não tem limites do ius civile, porque a família romana, como cada organismo político, tem em si a sua lei e os limites aos seus poderes. [...]” (BONFANTE, Pietro. Famiglia e Successione. Torino: Unione Toporgracio: Editrice Torinese, 1926, p. 12). 
Lo Stato, non che rispetti la morale, rispetta il diritto della famiglia; lo Stato in questo corpo autonomo non penetrò mai compiutamente, salvo per funzioni più essenziali all'esistenza sua, la milizia e la partecipazione alla sovranità política, nella sua sfera. Ma ridotta la questione in questi termini il contrasto sparisce. Non è giá che la civitas voglia ilimitata la potestà patria, ma soltanto che la potestà patria non ha limiti da lei, no ha limiti dal ius civile, perchè la famiglia romana, come ogni organismo político, ha in sè la sua legge e i limiti ai suoi poteri [...].

Há que se esclarecer, ainda, que, no tocante à "conuentio in manum", importa distinguir que: a) caso a mulher fosse filiasfamilias, já não tinha capacidade patrimonial, pois os bens concentravam-se no patrimônio do seu paterfamilias, portanto, apenas transferia a manus de titular, continuando, desse modo, a ora esposa sem patrimônio, pois os bens permaneciam com o seu pai; b) caso a mulher era sui iuris (ou seja, livre, por exemplo, na hipótese de que seu paterfamilias estivesse morto), sua capacidade patrimonial e todo o seu patrimônio passava para o marido ${ }^{17}$. É o que leciona Santos ${ }^{18}$ :

Três eram as principais formas de conuentio in manum: a confarreatio, a coemptio e o usus. A confarreatio era o casamento religioso e solene que consistia na oferta aos deuses de um pão ou bolo feito de uma espécie e trigo miúdo. [...] A coemptio, menos solene, era a compra simbólica da mulher [...] O usus era a permanência da mulher na posse de estado casado durante um ano, sem interrupção de três noites consecutivas.

Coulanges $^{19}$, a fim de descrever o que significa na sociedade romana o casamento cum manus, lecionou:

A mulher casada tem ainda o culto dos mortos; mas já não é aos antepassados que essa mulher oferece o banquete fúnebre, pois não mais tem direito. $\mathrm{O}$ casamento desligou-a por completo da família do pai e quebrou todas as ligações religiosas com ela. Agora, é aos antepassados de seu marido que vai levar a oferenda, agora que são de sua família e se tornaram seus antepassados.

Ad latere a estas regras da " $\mathrm{co}$ nuentio in manum”, o costume roma-

17 KASER, Max. Direito Privado Romano. Lisboa: Fundação Calouste Gulbenkian, 1999, p. 331.

18 SANTOS, Eduardo dos. Direito da Família. Lisboa: Almedina, 1985, p. 298.

19 COULANGES, Fustel de. A cidade antiga: estudos sobre o culto, o direito, as instituições da Grécia e de Roma. Tradução de Jean Melville. São Paulo: Martin Claret, 2001, p. 37. 
no exigia que o paterfamilias da esposa fizesse doações ao marido, o que foi denominado de dote (dos), como se depreende das célebres lições de Kaser $^{20}$ :

A celebração do matrimônio, como vimos, não produzia efeito jurídico imediato nas relações patrimoniais dos cônjuges; nem a conuentio in manum, quando se tratava de uma mulher sui iuris. Abstraindo deste último caso, o uso exige desde tempos antigos que o paterfamilias da mulher faça doações ao marido, por ocasião do matrimônio destes valores patrimoniais como dos (dote). Este dos cabe ao marido, que adquire a livre propriedade dos bens dotais. Em simultâneo, melhora-se a situação da mulher, porque o marido é moralmente obrigado em qualquer matrimônio - mesmo no sui iuris - a sustentá-la e fazê-la participar no seu nível de vida.

Incumbe destacar que importante momento histórico na vida romana, relativamente ao regime de bens matrimoniais, deu-se quando o Imperador Augusto, por volta do ano de 18 a.C., em face dos desfazimentos constantes das sociedades conjugais e das imoralidades ocorridas em detrimento das famílias, editou uma série de medidas denominadas leis matrimoniais, com o objetivo de manter os matrimônios existentes. As medidas, em um primeiro momento, foram vãs. Identificando-se resultados, se permitiu que a esposa buscasse a restituição de seu dote quando esta não desse causa ao desfazimento do vínculo. É o que se identifica no transcorrer do texto do jurista Aubéry ${ }^{21}$, a saber:

20 KASER, Max. Direito Privado Romano. Lisboa: Fundação Calouste Gulbenkian, 1999, p. 333.

21 "Augusto tentava remediar a desordem dos costumes e tendia a moralizar a união conjugal, a manter o casamento, rendê-lo fecundo, melhor assegurar a condição pecuniária das mulheres. Estas foram as leis Iulia de adulteriis, Iulia de maritandis ordinibus et Papia Poppea. Medidas que foram vãs. A primeira foi ineficaz, a tornar o casamento mais decente e a reafirmar a lei conjugal: as outras, mais conhecidas sobre a denominação de leis Caducaires, caíram no descrédito. O primeiro imperador, ao invés de favorecer a união dos interesses pecuniários dos esposos, agravou ainda mais a separação conjugal em proibir as mulheres de fazer algo por seus maridos. Deplorável, quase humilhante a situação das mulheres pela instabilidade do matrimônio. O marido podia apropriar-se do dote depois de ter expulsado sua esposa do lar conjugal. Um sério atentado voltou-se à união matrimonial. Tudo são e salvo deixando o princípio do divórcio, edita as medidas de precaução para poupar a mulher, ela conserva o seu dote, a possibilidade de um segundo casamento. Esse foi o objetivo da lei Iulia de fundo dotali, que permitia à mulher reclamar o seu aporte, a menos que ela divorciasse em motivo, isso fazia que ela perdesse parte considerável de seus bens (AUBÉRY, Gaëtan. La Communauté de Biens Conjugale. Paris: Libraire Générale de Droit \& Jurisprudence, 1911, p. 55). 
Auguste essaya de remédier au désordre des moeurs et tendant à moraliser l'union conjugale, à ramener au mariage, à le rendre fécond, à mieux assurrer la condition pécuniares des femmes. Telles furent les lois Iulia de adulteriis, Iulia de maritandis ordinibus et Papia Poppea. Mesures que restèrent vaines la première fut impuissante à rendre le mariage plus décent et à raffermir la foi conjugale: les autres plus connues sous la dénomination de lois Caducaires, tombèrent sous le discrédit. le premier empeurer, au lieu de favoriser l'union des intérêts pécuniares des époux, aggrava encore la séparation conjugale en interdisant aux femmes de s'engager pour leur maris. Déoplorabe, presque humiliante devint la situation de la femme par suite de instabilité du mariage. Le mari pouvait s'emparer de la dot aprés avoir chassé son épouse du foyer conjugal. Une sérieuse atteinte était ainsi portée à l'union matrimoniale. Tout en laissant sain et sauf le principe du divorce, on édicta des mesures de precáution pour ménager à la femme, en lui conservant sa dot, la possibilite d'un second mariage. Ce fut le but de la loi Iulia de fundo dotali, qui permit à la femme de reclamer la restituition de son apport, à moins qu'elle ne divorçât sans motif, ce que lui faisait perdre une partie notable de ses biens.

Há que ser ressaltado que na época pós-clássica, por influência cristã, as segundas núpcias (mesmo fora da viuvez), ainda que não diretamente proibida, eram sancionadas com desvantagens, inicialmente para a mulher que volta a casar e, posteriormente, para o marido. Essas medidas visam proteger o filho do casamento anterior, estabelecendo que a parte que volta a casar perde o patrimônio adquirido pelo casamento anterior, e representam as primeiras soluções para proteger o direito de terceiros, com limitação da autonomia da vontade $^{22}$. Importa destacar que a idade dos nubentes, em face do casamento, foi temática enfrentada pelas leis Julia e Papia, conforme C.5.4.27, a saber:

O mesmo Augusto a João, Prefeito do Pretório - Mandamos que as núpcias que foram proibidas pela Lei Julia ou Papia entre homens e mulheres maiores ou menores de sessenta ou de cinquenta anos não se impeçam de nenhum modo ou por parte alguma, querendo os homens contrair tais núpcias ${ }^{23}$.

22 KASER, Max. Direito Privado Romano. Lisboa: Fundação Calouste Gulbenkian, 1999, p. 323.

23 Texto em língua espanhola: “El mismo Augusto à Juan, Prefecto del Pretorio. - Mandamos que las nupcias que fueron prohibidas por la ley Julia ó Papia entre hombres y mujeres mayores o menores de sesenta o de cincuenta anos, no se impidan de ningún modo ó por parte de alguna, queriendo los hombres contraer tales nupcias” (JUSTINIANO, García Del Corral Ildefonso 1889. Cuerpo del Derecho Civil Romano. T. IV. Barcelona, 1889). 
Portanto, desde o Direito Romano já se verificava essa preocupação relativamente ao patrimônio da família, dos viúvos, bem como daqueles que tinham idade de sessenta anos, se homens, e cinquenta anos, se mulher. O crescimento do Cristianismo, sobretudo no governo do Imperador Constantino, favoreceu a defesa da mulher, concretamente com a imposição de garantias pecuniárias, em especial, contra os injustos repúdios feitos pelos romanos às suas mulheres, limitando o poder de repúdio a causas graves limitadas pela lei ${ }^{24}$.

Importante esclarecer que o direito dotal romano deu azo à espécie de regime de separação de bens, como se denota no ordenamento jurídico português, que assim o classifica, nos ensinamentos de Santos ${ }^{25}$.

Por sua vez, o direito matrimonial dos povos germânicos, também conhecidos como povos bárbaros, em face de não se expressarem em latim, é marcado pela viva inteligência, pelo pensamento elevado, pelos fortes laços constitutivos da família, que se fundava tanto na linha maternal como na paternal ${ }^{26}$. Há que salientar, para que seja possível compreender o regime matrimonial dos povos germânicos, que detinham um forte sentimento de dignidade moral, havendo respeito à sua esposa, sendo muito raros os casos de poligamia, estes restritos à classe rica $^{27}$. Aplicavam os germânicos, de igual forma, o regime dotal, no entanto, ao contrário de Roma, na Germânia, o marido é que atribuía um dote à mulher. É o que se concretiza no princípio de direito germânico: “dos ex marito”. Assim, o dote não era dado ao marido, pelo contrário, ofertado por ele, atendendo o antigo brocardo jurídico que diz: "Dotem non uxor marito, sed uxori maritus offert". ${ }^{28}$ Identificava-se, de igual forma, uma igualdade de condições entre as mulheres germânicas e seus maridos, tratando-se da verdadeira gênese de um regime matrimonial de comunhão de bens, do berço da comunhão de bens, nas palavras de Aubéry $^{29}$, a saber:

24 AUBÉRY, Gaëtan. La Communauté de Biens Conjugale. Paris: Libraire Générale de Droit \& Jurisprudence, 1911, p. 58.

25 SANTOS, Eduardo dos. Direito da Família. Lisboa: Almedina, 1985, p. 314.

26 AUBÉRY, Gaëtan. La Communauté de Biens Conjugale. Paris: Libraire Générale de Droit \& Jurisprudence, 1911, p. 69.

27 Ibidem, p. 72.

28 Ibidem, p. 72.

29 Tradução livre do autor: “Crê-se ver nos costumes da Germânia primitiva o berço da comunhão de bens. A vida nômade, a modicidade do valor dos objetos usuais, ausência de propriedade imobiliária teriam sido as circunstâncias para conduzir a uma comunhão de fato entre os esposos: para eles tudo devia se confundir” (Ibidem, p. 72). 
On a cru voir dans les moeurs de la Germanie primitive le berceau de la communauté conjugale. La vie nomade, la modicité de valeur des objects usuels, l'absence de proprieté immobilière auraient tout autant de circonstances devant entraîner forcément une communauté de fait entre les époux: pour eux tout devait se confondre.

É o que registra Pontes de Miranda ${ }^{30}$ :

Regime igualitário; Francos, Visigodos, Lombardos, Burgúndios. Se bem que os Romanos houvessem permitido entre os cônjuges a societas omnium bonorum, os costumes foram hostis, e é possível que alguns casos de comunhão a que os romanistas fazem referência tenham sido imitação dos chamados bárbaros.

Após as invasões, o povo germânico (bárbaro) modificou suas condições de vida, pois deixou a vida nômade, estabelecendo-se as famílias em regime agrícola, cultivando as terras conquistadas. A primeira movimentação dos germânicos foi buscar a aplicação de seus costumes, afastando o direito romano, no entanto, logo compreenderam que suas disposições costumeiras eram insuficientes, fazendo-se necessária uma maior complexidade de determinações, prosseguindo a obedecer ao Código de Teodosiano, vigente à época. Evidentemente que o convívio dos germânicos com os romanos trouxeram influências ${ }^{31}$.

Na Idade Média, curiosamente, a descentralização política, em face do feudalismo, fez renascer o espírito de unidade da família, do vínculo conjugal, bem como da consciência dos seus deveres daí decorrentes. $\mathrm{O}$ Cristianismo, de igual forma, passa a ser um grande motor no sentido de valorar a sua esposa e filhos. Destacou Aubéry ${ }^{32}$ :

Il est curieux de voir l'unité de la famille au milieu du démembrement politique. Nous avons déjà dit que le Christianisme, que fut le grande moteur des Croisades, prit une parte prépondérant dans cette oeuvre de relèvement de la femme et

30 PONTES DE MIRANDA, Francisco Cavalcanti. Tratado de Direito Privado. Tomo VIII, Rio de Janeiro: Borsoi, 1955, p. 211.

31 AUBÉRY, Gaëtan. La Communauté de Biens Conjugale. Paris: Libraire Générale de Droit \& Jurisprudence, 1911, p. 73.

32 Tradução livre do autor: "É curioso de ver a unidade da família no meio do desmembramento político. Nós tínhamos já dito que foi o grande motor das Cruzadas, tomou uma parte preponderante nesta obra de elevar novamente e afirmar que o homem não deve somente à sua pátria, como Roma, mas ainda a sua esposa e aos seus filhos" (Ibidem, p. 134). 
d'affermissement que l'homme ne se devait pas seulement à sa patrie, comme à Rome, mais encore à son épouse et à ses enfants.

De tal arte, na Idade Média, marcadamente volta-se ao regime de bens da comunhão de bens entre os esposos, decorrente da absorção do elemento galo-romano com o germânico $^{33}$. No reinado de Dom Afonso $\mathrm{V}$, no século $\mathrm{XV}$, realizou-se importante compilação da legislação portuguesa à época, que recebeu o nome de "Ordenações Afonsinas". Há que se destacar, em seu Livro IV, Título XII, que as Ordenações Afonsinas regulavam a matéria relativa ao regime matrimonial de bens, que assim dispunha:

O costume foi em esses Reinos de longamente usado, e julgado, que honde o casamento he feito antre o marido e a molher per Carta de meetade, ou em tal lugar, que per usança se partam os bens de por meo aa morte sem haver hy tal Carta, morto o marido, a molher fica em posse sem posse e Cabeça do casal $[\ldots]^{34}$ (grifo nosso).
Segundo Pontes de Miranda ${ }^{35}$, em que pese a aplicação da "Carta de metade" no período das Ordenações Afonsinas, havia lugares em que se aplicava, excepcionalmente, segundo o costume e a tradição, o regime matrimonial da separação de bens ou o regime dotal, como acontecia no Sul do Tejo. As Ordenações Manuelinas, em 1521, estabeleceram que o regime matrimonial de bens era o da comunhão universal de bens, a não ser que outro houvesse sido contratado, conforme seu Livro IV, Título 7, a saber:

Todos os casamentos que forem feitos em nossos reinos, e Senhorios, se entendem seer feitos por Carta de metade, salvo quando antre as partes outra cousa for acordado e contractado, porque entonce se guardará o que antre elles for concertado $^{36}$ (grifo nosso).

Assim, nas Ordenações Manuelinas, estabeleceu-se como regime matrimonial o de comunhão de bens, salvo quando não fosse convencionado outro em contrário, que poderia

33 Ibidem, p. 140.

34 PORTUGAL. Ordenações Afonsinas. Disponível em: <http://www1.ci.uc.pt/ihti/ proj/afonsinas/14p76.htm>. Acesso em: 20 jan. 2010.

35 PONTES DE MIRANDA, Francisco Cavalcanti. Tratado de Direito Privado. Tomo VIII, Rio de Janeiro: Borsoi, 1955, p. 212.

36 PORTUGAL. Ordenações Manuelinas. Disponível em: <http://www1.ci.uc.pt/ihti/ proj/afonsinas/14p76.htm>. Acesso em: 20 jan. 2010. 
ser da separação de bens ${ }^{37}$. Em 1603, as Ordenações Filipinas repetiram que: "Todos os casamentos que forem feitos em nossos reinos, e Senhorios, se entendem ser feitos por Carta de ametade, salvo quando entre as partes outra cousa fôr acordada e contractada, porque então será guardado o que entre elles fôr contractado"38. Pontes de Miranda ${ }^{39}$ acentua a origem da comunhão universal de bens aos povos germânicos, declarando sua influência nas Ordenações Afonsinas, Manuelinas e Filipinas.

Cumpre trazer a lume a gênese da separação obrigatória de bens na própria legislação portuguesa da época das Ordenações Filipinas, quando já havia preocupação por parte do Reino de Portugal de salvaguardar os filhos, em caso de segundas e terceiras núpcias, como se verifica pelo Alvará expedido sob a égide das Ordenações Filipinas, datado de 23 de novembro de $1770^{40}$ :

E pugnando outros pelo genuino e verdadeiro espirito della para se persuadirem, que em todos os casos, e muito especialmente naquelles, em que os patrimônios dos ditos viúvos, se compõem de dinheiro, peças de ouro e prata, e semelhantes moveis de facil distracção, não eram necessário esperarem-se os effectivos matrimonios, mas que bastava se possessem os viúvos em acto proximo de os contrahirem para logo se deverem applicar as referidas providencias; porque sendo aquelles bens de tão facil ocultação, e descaminho, presumiveis nos pais, que abandonando o amor paterno, se deixão arrastar por paixões tão lesivas aos filhos, serão inúteis as providencias de huma Lei que se dirigia a obviar aquelle prejuizo, se se applicassem depois que elle fosse huma vez inferido, e de se fazer isso irremediavel. [...] que os viúvos ou viuvas celebrem com effeito os segundos, ou terceiros casamentos; mas que basta somente se prove que elles ou ellas os tem ajustado, para que os filhos, ou quaesquer outros parentes possão requerer a Meza do Dezembargo do Paço ou aos Magistrados, a que pertencer, as providencias; quanto aos viúvos a facção do inventario e a caução de indemnidade; e quanto as viuvas, que se acho ordenadas no paragrapho vinte e nove da sobredita lei.

37 PONTES DE MIRANDA, Francisco Cavalcanti. Tratado de Direito Privado. Tomo VII, Campinas: Bookseller, 2000, p. 288.

38 PORTUGAL. Ordenações Filipinas. Disponível em: <http://www.ci.uc.pt/ihti/proj/ filipinas/14p832.gif>. Acesso em: 20 jan. 2010.

39 PONTES DE MIRANDA, op. cit., p. 213.

40 PORTUGAL. Alvará de 23 de setembro de 1770. Disponível em: <http://www.ci.uc. pt/ihti/proj/filipinas/14pa1062.htm>. Acesso em: 20 jan. 2010 
No tocante ao Código de Napoleão, de 1804, verifica-se que, em que pese ideário liberal, foi proclamado o poder marital em termos absolutos: “Artigo 213. O marido deve proteção a sua mulher, a mulher, obediência ao marido" ${ }^{41}$. No sentido de buscar pesquisar o maior número de diplomas legais que possam ter influenciado a legislação brasileira, que somente passou a tratar da matéria de forma codificada com o Código Civil Brasileiro de 1916, colacionam-se os artigos do Código Português de 1867, que tratava expressamente acerca da separação de bens, a saber: "Artigo 1.227: Nos casamentos feitos com separação de bens, cada um dos cônjuges conserva o domínio de tudo o quanto lhe pertence, podendo dispor dos respectivos bens livremente, salva a restrição imposta no artigo seguinte" ${ }^{42}$. Importa destacar que, em que pese não haver disposição expressa no capítulo próprio acerca de separação obrigatória de bens, já se pode identificar essa preocupação no dispositivo ora trazido, a fim de dar proteção aos bens para os filhos:

Artigo 1.237: A mulher que contrahir segundas núpcias após completar cincoenta anos, não poderá alhear por título algum desde o dia em que haja contrahido o segundo matrimonio, a propriedade de duas terças partes, dos bens mencionados no artigo 1235, em quanto tiver filhos e descendentes que possam haver ${ }^{43}$.

Sendo assim, há que se referir que, no panorama histórico desenvolvido, verificou-se a evolução dos regimes matrimoniais, de regimes primitivos completamente administrados pelo marido no Direito Romano (manus) para um regime de comunhão de bens, que deriva da vertente germânica. Mais particularmente, na história dos regimes matrimoniais de bens, identifica-se o Regime de Separação de bens, verificando que se tem notícia histórica do mesmo antes de integrar literalmente as Ordenações, como costume do reino, e, posteriormente, com as Ordenações Manuelinas, desenvolvendo-se até o Código Português de 1867, quando se tornou um dos regimes cabíveis que deveriam ser expressamente contratados pelos cônjuges. Ainda, depreende-se da legislação portuguesa a preocupação com a proteção dos viúvos e dos herdeiros, ante segundas núpcias, sendo gênese do dispositivo de separação obrigatória de bens.

41 SANTOS, Eduardo dos. Direito da Família. Lisboa: Almedina, 1985, p. 299.

42 PORTUGAL. Código Civil Português. Disponível em: <http://www.confap.pt/ docs/codcivil.PDF>. Acesso em: 20 jan. 2010.

43 Ibidem. 
Do relato trazido, depreende-se que, no transcurso da história, os povos, de uma forma ou de outra, buscaram dar proteção ao ente família, em face da importância no contexto social é o que Lepointe ${ }^{44}$ revela em sua obra “La Famille dans L’Ancien Droit”:

Mas além da vida física e corporal, a família desenvolveu um papel de primeira importância sob o ponto de vista social. Os povos, as nações valem após se mensurar o quanto vale a família. Diga-se que: "É sobre o joelho da mãe que se forma e que há o que é de maior e mais útil ao mundo: um homem honesto".

\subsection{Do regime obrigatório de separação de bens no Código Civil Brasileiro}

Após a vigência na então República dos Estados Unidos do Brasil das Ordenações Filipinas, a Lei n. 3.071 de $1^{\circ}$ de janeiro de 1916 , intitulado Código Civil Brasileiro, entrou em vigor no dia $1^{\circ}$ de janeiro de 1917 , revogando expressamente em seu artigo 1.807 as Ordenações e alvarás do Reino Português. O Código Civil Brasileiro de 1916, conformando-se em uma codificação genuinamente brasileira, regulou a matéria pertinente aos regimes matrimoniais de bens, dando o seguinte trato, no tocante ao regime obrigatório de separação de bens:

Art. 258. Parágrafo único. É, porém, obrigatório o da separação de bens do casamento: I - Das pessoas que o celebrarem com infração do estatuído no art. 183, XI a XVI (art. 216); II - do maior de 60 (sessenta) e da maior de 50 (cinquenta) anos; III - do órfão de pai e mãe, ou do menor, nos termos dos arts. 394 e 395, embora case, no termos do art. 183, XI, com o consentimento do tutor; (Redação dada pelo Decreto do Poder Legislativo $\mathrm{n}^{\circ}$ 3.725, de 15.1.1919). IV - de todos os que dependerem, para casar, de autorização judicial (arts. 183, XI, 384, III, 426, I, e 453). (Redação dada pelo Decreto do Poder Legislativo $\mathrm{n}^{\circ}$ 3.725, de 15.1.1919) ${ }^{45}$.

Portanto, verifica-se que a finalidade da norma foi assegurar o direito dos órfãos, dos menores ${ }^{46}$ que casam,

44 LEPOINT, Gabriel. La Famille das L'Ancien Droit. Paris: Éditions Domat Montchrestien, 1947, p. 2.

45 BRASIL. Lei $n^{\circ}$ 3.071, de 1 de janeiro de 1916, da República Federativa do Brasil. Brasília, DF. Disponível em: <http://www.planalto.gov.br/ccivil_03/Leis/L3071.htm>. Acesso em: 20 jan. 2012.

46 Expressão atualmente substituída por "criança” ou "adolescente” pela doutrina jurídica nacional, com base em um processo evolutivo acerca da evolução histórica da família (ROSA, Conrado Paulino da. Desatando Nós e Criando Laços. Belo Horizonte: Del Rey, 2012). 
e, de igual forma, estendeu a proteção à defesa do patrimônio dos maiores de sessenta anos e das maiores de cinquenta anos, limitando, portanto, a sua autonomia de vontade destes, no sentido de não ser possível escolherem os regimes aplicáveis no direito brasileiro à época (comunhão universal de bens, comunhão parcial de bens, regime dotal e regime de separação convencional). Nader ${ }^{47}$ assim acentua acerca do Código de 1916:

Pelo Código de 1916 (art. 258, inciso II), aquele limite se destinava apenas ao homem, enquanto para a mulher a previsão era de cinquenta anos. $\mathrm{Na}$ visão do legislador, a partir de certa idade a pessoa se tornaria suscetível de sofrer o que, na boa gíria, costuma se designar por "golpe do baú". A fim de proteger os interesses da prole, o legislador impõe a separação, impedindo destarte a comunhão dos bens existentes anteriormente ao casamento. Uma outra razão seria quanto à expectativa de vida que, não sendo grande, não justificaria um regime que instaurasse a comunhão dos bens anteriores existentes.

Gonçalves $^{48}$ refere:

A restrição é eminentemente de caráter protetivo. Objetiva obstar à realização de casamento exclusivamente por interesse econômico. O Código Civil de 1916 impunha o regime de separação somente ao homem com mais de 60 anos. Para a mulher, o limite de idade era de 50 anos.

Venosa ${ }^{49}$, de igual forma, manifestou-se:

Quanto ao casamento do maior de 60 e da maior de 50 anos no Código de 1916, o legislador compreendeu que, nessa fase da vida, na qual presumivelmente o patrimônio de um ou de ambos os nubentes já está estabilizado, e quando não mais consorciam no arroubo da juventude, o conteúdo patrimonial deve ser peremptoriamente afastado. A ideia é afastar o incentivo patrimonial do casamento de uma pessoa jovem que se consorcia com alguém idoso.

Com o advento do Código Civil de 2002, Lei n. 10.406, de 10 de janeiro de 2002, inicialmente, pouco se modificou no tocante à matéria, apenas havendo uma uniformização para sessenta anos, todavia, em momento posterior, em face de verdadeira manifestação da sociedade civil, foi aumentada a idade para setenta anos, a partir da Lei n. 12.344, de 2010, independente do fato de o cônjuge ser

47 NADER, Paulo. Curso de Direito Civil. Rio de Janeiro: Forense, 2006, p. 441. 48 GONÇALVES, Carlos Roberto. Direito Civil Brasileiro. V. VI. 5. ed. São Paulo: Saraiva, 2008, p. 417.

49 VENOSA, Silvio de Salvo. Direito de Família. V. 6. São Paulo, Atlas, 2003, p. 175. 
homem ou mulher. É o que dispõe o artigo 1.641 , $\mathrm{II}^{50}$ :

É obrigatório o regime da separação de bens no casamento: I - das pessoas que o contraírem com inobservância das causas suspensivas da celebração do casamento; II - da pessoa maior de setenta anos; III - de todos os que dependerem, para casar, de suprimento judicial.

Portanto, em que pese a modificação legislativa noticiada, manteve o Código Civil de 2002 a proteção aos menores, aos filhos, bem como ao patrimônio do maior de setenta anos, estabelecendo, ao desejar se casar, limite ao princípio da autonomia da vontade. É o que justificou, à época, o Senador Josaphat Marinho na manutenção do artigo 1.641, II, do Código Civil Brasileiro, como leciona Monteiro $^{51}$ :

Trata-se da prudência legislativa em favor das pessoas e de suas famílias, considerando a idade dos nubentes. É de lembrar que, conforme os anos passam, a idade avançada acarreta maiores carências afetivas e, portanto, maiores riscos corre aquele que tem mais de sessenta anos de sujeitar-se a um casamento em que o outro nubente tenha em vista somente vantagens financeiras. Possibilitar, por exemplo, a adoção do regime de comunhão universal de bens, num casamento assim celebrado, pode acarretar consequências desastrosas ao cônjuge idoso, numa dissolução inter vivos de sua sociedade conjugal, ou mesmo a seus filhos, numa dissolução causa mortis do casamento.

Com a devida vênia, novos rumos precisam ser tomados, em face dos fundamentos que seguem.

\section{NOVOS RUMOS PARA O REGIME MATRIMONIAL DE BENS AO CÔNJUGE MAIOR DE SESSENTAANOS}

\subsection{Dos fundamentos para uma nova perspectiva}

\subsubsection{Da adequação do atual} Regime Obrigatório de Separação de Bens feita pela jurisprudência em face do Princípio do não enriquecimento sem causa

Cumpre destacar que o regime obrigatório de separação de bens descrito no Código Civil Brasileiro já

50 BRASIL. Lei $n^{o}$ 10.406, de 10 de janeiro de 2002, da República Federativa do Brasil. Brasília, DF. Disponível em: <http://www.planalto.gov.br/ccivil_03/LEIS/2002/ L10406compilada.htm>. Acesso em: 20 jan. 2012.

51 MONTEIRO, Washington de Barros. Curso de direito civil. V. 2. Direito de família. Atualizado por Regina Beatriz Tavares da Silva. 37. ed. São Paulo: Saraiva. 2004, p. 218. 
não vem atendendo aos anseios dos jurisdicionados brasileiros, o que de per se denota a necessidade de alterações legislativas. Por isso, pode-se afirmar que a literalidade do que consta no Código Civil Brasileiro, a partir da maturação jurisprudencial, identificou que a mera aplicação ao caso concreto dos dispositivos legais fomentaria o enriquecimento sem causa. De tal arte, deve a norma jurídica, no contexto do ordenamento jurídico, ser interpretada à luz dos princípios gerais de direito, observando a subsunção do direito ao caso concreto, que se materializa pela jurisprudência dos Tribunais. Visitando a Teoria do Ordenamento Jurídico, Bobbio ${ }^{52}$, coconstrutor da Escola Italiana do Positivismo Analítico, referiu que:

L'esigenza della nuova ricerca nasce dal fatto Che nella realtà Le norme giuridiche non esistono mai da sole, ma sempre in um contesto di norme, Che hanno particolari rapporti tra loro (e questi rapporti saranno in gran parte l'oggetto della nostra tratazione”. Questo contesto di norme di suole chiamare "ordinamento".

Romano ${ }^{53}$ que, igualmente, trata acerca desse tema, referiu que o Ordenamento Jurídico não é a simples soma dos pedaços, que são as normas, aduzindo que a vontade, o poder, a mens do Ordenamento Jurídico são distintos das normas individuais e independentes, constituindo um "todo vivente”, um organismo. O Ordenamento Jurídico tem força própria, valendo-se de uma interpretação evolutiva, ou seja, a vontade do Ordenamento Jurídico é suscetível de mudar, sem que se incorporem novas normas, apenas alterando o ambiente social em que se deve encontrar a aplicação.

É o que se verifica quando se observou que a aplicação nua e crua do regime obrigatório de separação de bens constante no Código Civil Brasileiro acabava ferindo frontalmente os princípios gerais de direito, como o princípio do não enriquecimento sem causa, pois um dos cônjuges, ainda

52 Tradução livre do autor: "A exigência da nova pesquisa nasce do fato que, na realidade, as normas jurídicas nunca existem sós, mas sempre em um contexto de normas, que estabelecem relações entre elas (e essas relações serão parte do objeto da nossa análise). Esse contexto de norma é chamado costumeiramente de ordenamento" (BOBBIO, Norberto. Teoria dell’Ordinamento Giuridico. Torino: Giappichelli, 1960, p. 3).

53 "Così, per esempio, si parla di uma volontà, di una potestà, di una mens di uma forza propria dell'ordinamento giuridico, distinta da quella delle singole norme e indipendente anche dalla volontà del legislatore che le ha emanate; si afferma che l'ordinamento medesimo costituisce un 'tutto vivente' un 'organismo', che ha quella 'forza propria, sebbene latente, di espansione e di adattamento' sulla quale si Fonda l'ammissibilità dell'analogia” (ROMANO, Santi. L'ordinamento giuridico. Firenze: Sansoni, 1951, p. 13). 
que tenha contribuído para a aquisição de um bem, no entanto, como não consta como de sua titularidade, não teria direito algum sobre o mesmo. O princípio do não enriquecimento sem causa está entre aqueles que são basilares de qualquer Ordenamento Jurídico, basta verificar que as Institutas do Imperador Justiniano referem que: "Os preceitos do direito são os seguintes: viver honestamente, não lesar os outros, dar a cada um o que é seu" ${ }^{54}$ (grifo nosso).

Com a devida vênia, a exclusão de direitos promovida pelo regime obrigatório de separação de bens, efetivamente, é aplicar o brocardo de forma inversa, qual seja: "não dar a cada um o que é seu”. Importa destacar, que, para melhor compreender a matéria, há que ter em conta que o regime obrigatório de separação de bens foi introduzido no Brasil, à época, em que, na ausência de disposição em contrário, aplicava-se o regime de comunhão universal de bens. Saliente-se que somente com a Lei 6.515 de 26 de dezembro de 1977, é que passou a ser a comunhão parcial de bens $^{55}$. Nesse sentido, antes da mencionada alteração legislativa, poderia alguém desavisado, e, portanto, tendo se quedado silente, matrimoniar-se e, com isso, em face do regime vigente à época, entregar ao outro cônjuge a metade de seus bens conquistados até o momento da celebração do matrimônio. Ocorre que, atualmente, isso não é mais possível, visto que o estabelecimento do regime matrimonial de comunhão parcial de bens passa a ser regra no silêncio dos contraentes, apenas atingindo os bens havidos na constância do casamento.

A partir da ofensa ao princípio do não enriquecimento sem causa, o Supremo Tribunal Federal, ainda sob a vigência do Código Civil de 1916, editou Súmula 377 com o seguinte conteúdo: "no regime de separação legal de bens, comunicam-se os adquiridos na constância do casamento". Portanto, a jurisprudência, na prática, acabou por corrigir as imperfeições legislativas. Na linha do afirmado por Madaleno $^{56}$, tal Súmula acaba por eli-

54 JUSTINIANUS, Flavius Petrus Sabbatius. Institutas. Tradução e notas de Edson Bini. Bauru: EDIPRO, 2001,. p. 21.

55 “Art. 258. Não havendo convenção, ou sendo nula, vigorará, quanto aos bens entre os cônjuges, o regime de comunhão parcial” (Redação dada pela Lei ${ }^{\circ}$ 6.515, de 26.12.1977) (BRASIL. Lei $n^{\circ}$ 3.071, de 1 de janeiro de 1916, da República Federativa do Brasil. Brasília, DF. Disponível em: <http://www.planalto.gov.br/ccivil_03/Leis/ L3071.htm>. Acesso em: 20 jan. 2012).

56 MADALENO, Rolf. Regime de bens entre os cônjuges. Direito de Família e o novo Código Civil. Belo Horizonte: Del Rey, 2001, p. 176-178. 
minar o regime obrigatório de bens, permanecendo apenas o regime de separação de bens convencional. É o que refere Venosa ${ }^{57}$ :

A jurisprudência, no entanto, procurou abrandar iniquidades em casos concretos trazidos pelo texto objetivo da lei, como apontamos. A maioria dos casamentos realizados sob o regime de separação legal é de jovens que amealham seu patrimônio no curso do casamento. Seria injusto, em princípio, não se comunicarem os bens adquiridos pelo esforço comum. A ideia, todavia, é de que, mesmo se casando sob o regime de separação, durante o casamento estabelece-se uma sociedade de fato entre os esposos, e os bens são adquiridos pelo esforço comum.

RessaltaVenosa ${ }^{58}$, advertindo acerca de entendimentos em contrário:

Por outro lado, como aponta Silvio Rodrigues, se o legislador quisesse determinar que o casamento fosse regido pela comunhão parcial, não se teria referido ao regime de separação, como faz o art. 258, mas expressamente ao regime da comunhão par- cial. [...] Não entendemos, contudo, que a questão se encontra isenta de discussões. A súmula não ressalva que os bens que se comunicam são os comprovadamente decorrentes do esforço. Essa matéria é daquelas nas quais há um descompasso entre a doutrina e a jurisprudência.

De tal arte, eis o fundamento primeiro para o impulso a mudanças legislativas, além da violação ao princípio do não enriquecimento sem causa, dá-se a própria insegurança jurídica nas relações matrimoniais.

\subsubsection{Do Princípio da Autonomia de Vontade}

Segundo Savatier ${ }^{59}$, a autonomia da vontade é o princípio que submete a criação do direito à vontade humana, encontrando seus limites na ordem pública, a saber:

L'autonomie de la volonté, c'est le principe soumettant la création du droit à la volonté humaine. Celle-ci est libre de passer les actes que lui plaisent; en particulier, les hommes sont libres de se lier entre eux par des

57 VENOSA, Silvio de Salvo. Direito de Família, V. 6. São Paulo, Atlas, 2003, p. 176. 58 Ibidem, p. 177.

59 Tradução do autor: “A autonomia da vontade é o princípio que submete a criação do direito à vontade humana. Esta é livre de realizar os atos que desejar; em particular, os homens são livres de se ligar entre eles por contratos, fazendo nascer assim, um com o outro, tais relações de direito que a eles convêm. Mas essa liberdade tem os limites tirados das necessidades sociais. Esses limites constituem o que se chama de ordem pública” (SAVATIER, René. Cours de Droit Civil. 2. ed. 1947, p. 26). 
contrats, faisant naître ainsi, de l’un à l'autre, tels rapports de droit qui leur conviennent. Mais cette liberté a des limites tirées des necessites sociales. Ces limites constituent ce qu'on appelle ordre public.

Nesse sentido, para que se estabeleçam limites à autonomia da vontade, há que existir fundamentos jurídicos para tanto, efetivamente justificáveis em face dos valores que apóiam o Ordenamento Jurídico, por motivos de ordem pública. O Código Civil Francês, em seu artigo 1.387, proclama a liberdade das convenções matrimoniais, permitindo aos cônjuges que "façam como julgar" seu regime de bens, desde que não seja contrário aos bons costumes e às disposições legais. Estes, portanto, são os únicos casos de limites da autonomia da vontade, a saber: "La loi ne regit l'association conjugale, quant aux biens, qu'à defaut de conventions spéciales, que les époux peuvent faire comme ils le jugent à propos, pourvu q'elles ne soient pas contraires aux bonnes moeurs ni aux dispositions que suivent" ${ }^{60}$.

O Direito Francês, portanto, admite a liberdade de convenções, e, no silêncio das partes, tem como regime de bens a comunhão legal, nos termos do artigo 1.400 do Código Civil Francês: "La communauté, qui s'etablit à defaut de contrat ou par la simples déclaration qu'on se marie sous le régime de la communauté,est soumise aux régles expliquées dans les trois section que suivent" ${ }^{61}$.

Conforme Mazeaud e Mazeaud ${ }^{62}$, o regime matrimonial de bens pode ser pactuado livremente por todo aquele que está apto ao casamento, não havendo, portanto, as limitações de autonomia de vontade, a saber: “c'est la régle: Habilis ad nuptias, habilis ad pacta nuptiala”. Na França, portanto, não há regime obrigatório de separação de bens, uma vez que esse regime se dá em dois casos: a) separação convencional, quando os esposos adotam

60 Tradução livre do autor: A lei rege a associação conjugal quanto aos bens, na falta de convenções especiais, os esposos podem fazer como eles julguem oportuno, desde que eles não sejam contrários aos bons costumes, nem aos dispositivos que seguem (FRANÇA. Código Civil Francês. 107. ed. Paris: Dalloz, 2008, p. 1.633).

61 Tradução livre do autor: A comunhão, que se estabelece na falta de contrato ou pela simples declaração que se casam sob o regime da comunhão, é submissa às regras explicadas nas três seções que seguem (FRANÇA. Código Civil Francês. 107. ed. Paris: Dalloz, 2008, p. 1.645).

62 Tradução livre do autor: É a regra: apto para casar, apto para pactuar o regime de bens (MAZEAUD, Henri et Léon; MAZEAUD, Jean. Leçons de Droit Civil. Paris: Éditions Montchrestien. 1955, p. 1.112). 
esse regime no contrato de casamento, nos termos do artigo 1536 do Código Civil Francês: "Lorsque les époux ont stipulé dans leur contrat de mariage qu'ils seraient separes de biens, chacun d'eux conserve l'administration, la jouissance et la libre disposition de ses biens personelles”63; b) separação judicial, quando requerido a título de sanção, nos termos do artigo 1.443 do Código Civil Francês (separação judicial de bens):

Si, par le désordre des affaires d'un époux, sa mauvaise administration ou son inconduite, il apparaît que le maintien la communauté met en péril les intêrets de l'autre conjoint, celui ci peut poursuivre la séparation e biens en justice ${ }^{64}$.

No que é pertinente ao Direito Italiano, acerca da relação entre o princípio da autonomia da von- tade e o Direito de Família, cumpre colacionar importante colaboração de Zoppini ${ }^{65}$, em artigo intitulado "L'autonomia privata nel Diritto di Famiglia Sessant'anni dopo", na "Rivista di Diritto Civile”, que defende a aplicação do princípio nesse campo do Direito, a saber:

Il possibile uso distorto dell'autonomia negoziale non giustifica, tuttavia, la conclusione che nel diritto di famiglia il paternalismo del legislatore sia preferibile all'autonomia dei contraenti: il controllo fondato sulla nullità è senz'altro il meno efficiente, atteso che sacrifica indistintamente anche gli accordi che garantiscono assetti ottimali nel organizzazzione degli interessi familiari; al contempo, in termini di politica del diritto, la promozione dell'egualianza morale e giuridica non si realizza attraverso norme de divieto que limitino l'autonomia individuale.

63 Tradução livre do autor: No momento em que os esposos estipularam em seu contrato de casamento que eles teriam separados os seus bens, cada um deles conserva a administração, gozo e a livre disposição dos bens pessoais (FRANÇA, op. cit., p. 1.701). 64 Tradução livre do autor: Se pela desordem de negócios de um esposo, sua má administração ou sua negligência, constata-se que ele coloca a comunhão em perigo e os interesses do outro cônjuge, este pode buscar a separação de bens na justiça (Ibidem, p. 1.679).

65 Tradução livre do autor: O possível mau uso da autonomia negocial não justifica, todavia, a conclusão que no direito de família o paternalismo do legislador seja preferível à autonomia dos contraentes: o controle fundado sobre a nulidade é, sem dúvida, o menos eficiente, considerando que sacrifica indistintamente também os acordos que garantem ordens ótimas na organização dos interesses familiares; ao mesmo tempo, em termos de política de direito, a promoção da igualdade moral e jurídica não se realiza pela proibição que limite a autonomia individual” (ZOPPINI, Andrea. L'autonomia privata nel Diritto di Famiglia, sessant'anni dopo. Rivista di Diritto Civile. Padova: CEDAM Casa Editrice Dott. Antoni Milani, Ano XLVIII, Mar./Apr. 2002, p. 227). 
O Direito Italiano, dessa forma, consagra a autonomia da vontade ao dispor em seu artigo 159 que: "Il regime patrimoniale legale della famiglia, in mancanza di diversa convenzione stipulata a norma dell'articolo 162, è costituito dalla comunione dei beni regolata dalla sezione III del presente capo" ${ }^{66}$. Por sua vez, o artigo 162 do Código Civil Italiano admite a separação convencional de bens, a saber: "La scelta del regime di separazione può anche essere dichiarata nell'atto di celebrazione del matrimonio" ${ }^{67}$.

Tedeschi6 ${ }^{68}$ a seu modo, em sua obra "Il Regime Patrimoniale della Famiglia”, ressaltou o princípio da liberdade das convenções, referindo que as limitações a essa autonomia somente se dariam no caso dos direitos de família não patrimoniais, a saber:
La libertà delle convenzioni matrimoniali è fondamentalmente risconosciuta dall'art. 159 do cod. Cciv [...] Le restrizioni a questa autonomia dei privati risultano da tutto il sistema della nostra legge, e specialmente dalla natura cogente di alcune norme di diritto familiare; ciò richiama l'art. 160. [...] L'art. 160 si riferisce anzitutto ai principii di diritto di famiglia non patrimoniale [...] Tra i diritti che appartengono al capo della famiglia, dal punto di vista non patrimoniale, si distinguono quelli che gli appartengono como marito e quelli che gli appartengono come padre. In relazione ai primi, costituenti la potestá maritale, sarebbe nullo il patto con cui si permettesse alla moglie la scelta del domicilio coniugale.

De tal arte, na Itália, há plena autonomia de vontade, no que toca ao regime de bens, por se tratar a escolha de regime de bens de direito de família patrimonial.

66 "O regime patrimonial legal da família, na falta de diferente convenção estipulada na norma do artigo 162, é constituído o regime de comunhão de bens regulada na seção III do presente caput” (ITÁLIA. Codice Civile. Milano: Egea, 2008, p. 50).

67 "A escolha do regime de separação pode ser declarada também no ato da celebração do matrimônio” (Ibidem, p. 51).

68Traduçãolivre do autor:Aliberdade das convenções matrimoniais éfundamentalmente reconhecida do artigo 159 do Código Civil. As restrições a essa autonomia dos privados resultam de tudo do sistema da nossa lei e, especialmente, da natureza cogente de algumas normas de direito de família; isso reclama o artigo 160. [...] O artigo 160 se refere acima de tudo aos princípios de direito de família não patrimonial. [...] Entre os direitos que pertencem ao chefe da família, do ponto de vista não patrimonial, distinguem-se daqueles que lhe pertencem como marido e aqueles que lhe pertencem como pai. Em relação aos primeiros, constituem o poder marital, seria nulo o pacto em que se permitisse à mulher a escolha do domicílio conjugal (TEDESCHI, Guido. Il Regime Patrimoniale della Famiglia. 3. ed. Torino: Unione Tipográfico Editrice Torinese, 1956, p. 40). 
Em Portugal, por outro lado, o regime matrimonial de bens estabelece limitação à autonomia da vontade, aplicando limite etário de sessenta anos. É o que se depreende do Código Civil Português de 1966, em seu artigo 1.720, que trata do intitulado "Regime imperativo da separação de bens”, a saber:

Artigo 1720. 1. Consideram-se sempre contraídos sob o regime da separação de bens: a) O casamento celebrado sem precedência do processo de publicações; b) O casamento celebrado por quem tenha completado sessenta anos de idade. 2 . O disposto no número anterior não obsta a que os nubentes façam entre si doações. (Redaç̧ão do Dec.-Lei 496/77, de 25-11) $)^{69}$.

Como visto anteriormente, o Direito Português, desde 1770, já contava com alvará do Reino, que se preocupava com as paixões dos senhores viúvos, que haviam reunido fortuna em sua vida.

O Direito Brasileiro, como já mencionado, também aplica o regime obrigatório de separação de bens para os maiores de setenta anos, sofrendo severas críticas. Francisco José Cahali, atualizando a obra de Rodrigues ${ }^{70}$, referiu, diante da original redação do Código Civil de 2002, que:

Talvez se possa dizer que uma das vantagens da fortuna consiste em aumentar os atrativos matrimoniais de quem a detém. Não há inconveniente social de qualquer espécie em permitir que um sexagenário ou uma sexagenária ricos se casem pelo regime de comunhão, se assim lhes aprouver.

Há que se referir que parte da doutrina fundamenta seu entendimento no princípio da isonomia, constante do artigo $5^{\circ}$ da Constituição da República Federativa do Brasil, como faz Martins e Boiago Junior ${ }^{71}$, para se posicionar de forma diversa à sua aplicação:
À luz da Constituição Federal, a restrição imposta pelo legislador do Código Civil não prospera, haja vista, o princípio isonômico de todos serem tratados de forma paritária, sem qualquer discriminação em relação

69 PORTUGAL. Código Civil Português. Disponível em: <http://www.confap.pt/ docs/codcivil.PDF>. Acesso em: 20 jan. 2010.

70 RODRIGUES, Sílvio. Direito civil: direito de família. 28. ed. rev. e atul. por Francisco José Cahali. V. 6. São Paulo: Saraiva, 2006, p. 144-145.

71 MARTINS, Fabiane Parente Teixeira; BOIAGO JÚNIOR, José Wilson. Questões controvertidas sobre a mutabilidade do regime de bens para as causas ensejadoras da separação obrigatória. Revista Nacional de Direito e Jurisprudência, n. 94, ano 8, out. 2007, p. 57. 
ao sexo e à idade, não podendo a senilidade ser considerada forma natural de incapacidade.

Por outro lado, refere Monteiro ${ }^{72}$ :

Com o devido respeito pelas posições contrárias ao regime de separação de bens e sua aplicabilidade obrigatório aos casamentos daqueles que contam com mais de sessenta anos de idade, é preciso lembrar que o direito à liberdade, tutelado na Lei Maior, em vários incisos de seu art. $5^{\circ}$, é o poder de fazer tudo o que se quer, nos limites resultantes do ordenamento jurídico.

Revelam-se, portanto, interessantes posicionamentos.

\subsection{Uma perspectiva acerca do regime matrimonial obrigatório de separação de bens ao maior de setenta anos}

Com base na análise histórica do instituto em tela, depreende-se que o Regime Obrigatório de Separação de Bens aos maiores de setenta anos teve seu nascedouro pari passu com a preocupação havida relativamente às viúvas e viúvos, que, após amealharem um patrimônio de uma vida, po- deriam vir a perdê-lo pelas segundas núpcias, em detrimento de seus filhos ou herdeiros, dispersando o capital reunido do âmago de sua família. Importa salientar que, em determinados diplomas legislativos, confundem-se a exigência mínima de idade e o estado civil de viuvez. É o que ocorreu, por exemplo, com a legislação portuguesa desde os alvarás e ordenações de Reino.

Cumpre referir que apenas o requisito idade máxima de setenta anos não pode figurar como determinante para que o indivíduo tenha que se matrimoniar pelo regime obrigatório de bens. Ora, a proteção dos interesses dos infantes, dos filhos das primeiras núpcias, deve permanecer. É isso que deve ser tutelado pelo Estado, e não o interesse do maior de setenta anos, que efetivamente não se configura de ordem pública, sendo situação adstrita à esfera privada do indivíduo.

Como se verificou, tal situação que determina a separação obrigatória para os maiores de setenta anos, além de incentivar a insegurança jurídica, fere frontalmente o princípio do não enriquecimento sem causa. Convém reprisar que o próprio Direito Romano excluiu o limite de idade para casamento. O Direito Italiano e o Direi-

72 MONTEIRO, Washington de Barros. Curso de direito civil. V. 2. Direito de família. Atualizado por Regina Beatriz Tavares da Silva. 37. ed. São Paulo: Saraiva, 2004, p. 217-218. 
to Francês, objetos de estudo, muito bem demonstraram que, não havendo ofensa à ordem pública, não há como ingressar na esfera patrimonial do indivíduo.

Ademais, como se verificou da doutrina, em especial a italiana, os regimes matrimoniais fazem parte do direito patrimonial de família, portanto, deve haver severo abrandamento da intervenção estatal, contrariamente a outras situações jurídicas do Estatuto Pessoal, como nome, domicílio, paternidade e filiação. Portanto, dentro dessa fundamentação, a perspectiva proposta é de alteração legislativa para que seja retirada do rol do artigo 1.641 do Código Civil a determinação de regime obrigatório de separação de bens ao maior de setenta anos, permitindo que ele possa escolher, e, no seu silêncio, aplique-se o regime de bens da comunhão parcial de bens, como dispõe o ordenamento jurídico. Ora, se o maior de setenta anos desejar casar com a comunhão universal de bens, fará o pacto antenupcial, dentro dessa nova perspectiva, e, mesmo nesse regime, à luz do direito sucessório, não retira o direito dos herdeiros, devendo poder fazê-lo.

Ademais, importa destacar que o indivíduo maior de setenta anos, como todo e qualquer jurisdicionado, não perderá o direito de exercer o que preceituam os artigos 1.548 e 1.550 do Código Civil Brasileiro, que se voltam a situações de invalidade e de anulabilidade do casamento, visto que: aquele que casou sem o necessário discernimento, por ser enfermo mental (artigo 1.548, I do CCB), bem como aquele que se casou manifestando sua vontade eivada por vício, por erro essencial ou coação (artigo 1.550 , III), em ambos os casos poderão buscar a tutela jurisdicional. É nesse sentido que se compreende a matéria, no sentido de excluir o maior de setenta anos entre aqueles que tenham que obrigatoriamente casar em regime de separação de bens, reservando-lhe o direito de buscar a invalidade e anulabilidade do matrimônio, quando for o caso.

\section{CONSIDERAÇÕES FINAIS}

Com base na pesquisa realizada, em nível histórico, bem como nas fontes do Direito Comparado, tornou-se possível tecer as seguintes considerações finais, a saber:

Verificou-se que no transcorrer da história da humanidade sempre houve preocupação acerca dos regimes matrimoniais de bens, no sentido da proteção da família, dos filhos menores, dos herdeiros e das pessoas de idade avançada, que possuíam patrimônio.

Analisou-se a legislação brasileira, apreendendo-se que esta, atualmente, não responde aos interesses dos jurisdicionados, mormente em face da aplicação de Súmula 377 do 
Supremo Tribunal Federal, válvula para soluções de injustiças em casos concretos.

Que a aplicação apenas dos dispositivos do Código Civil Brasileiro vigente acaba por gerar violação ao princípio do não enriquecimento sem causa, visto que os cônjuges contribuem mutuamente para a aquisição de patrimônio e, no regime obrigatório de separação de bens, sem a aplicação da Súmula 377 do Supremo Tribunal Federal, não é alcançado ao cônjuge qualquer direito relativamente ao bem que não está registrado em sua titularidade.

Identificando-se a situação de iniquidade no caso concreto, passou-se a analisar o princípio do não enriquecimento sem causa e sua necessária aplicabilidade em matéria de regime de bens.

Estabeleceu-se a importância do princípio da autonomia da vontade, classificando-se os regimes matrimoniais de bens em direito patrimonial de família, que, portanto, permite maior autonomia da vontade, ao contrário daquelas situações em que se configuram direito pessoal de família, como o caso do nome e filiação.

À luz do Direito Comparado moderno, bem como da doutrina brasileira, esquadrinhou-se os posicionamentos aplicáveis.

Apresentou-se uma perspectiva para o instituto no sentido de retirar do rol de casos de regime obrigatório de separação de bens os maiores de setenta anos, em face de sua autonomia de vontade, não sendo o caso de ofensa à ordem pública o seu direito de escolha.

Permitir, inclusive, que os maiores de setenta anos possam optar pelo regime de comunhão universal, desde que feito com pacto antenupcial, na forma da lei pátria, ressaltando que não ofenderá, de igual forma, a herança de seus sucessores.

Destacar que o indivíduo maior de setenta anos, como todo e qualquer jurisdicionado, não perderá o direito de exercer o que preceituam os artigos 1.548 e 1550 do Código Civil Brasileiro, que se voltam à situações de invalidade e de anulabilidade do casamento, visto que: aquele que casou sem o necessário discernimento, por ser enfermo mental (artigo 1.548, I do CCB), bem como aquele que se casou manifestando sua vontade eivada por vício, por erro essencial ou coação (artigo 1.550, III), em ambos os casos, poderão buscar a tutela jurisdicional.

Referir que a matéria é árida, mas que merece urgente tratamento legislativo, em face da insegurança jurídica e potenciais situações de enriquecimento ilícito promovidas pelo próprio ordenamento jurídico, tolhendo o direito daqueles que laboraram conjuntamente para a construção de um patrimônio, ferindo o brocardo jurídico romano que determina que seja “dado a cada um o que é seu”. 


\section{REFERÊNCIAS}

ALVES, José Carlos Moreira. Direito Romano, Rio de Janeiro: Forense, 2008.

AUBÉRY, Gaëtan. La Communauté de Biens Conjugale. Paris: Libraire Générale de Droit \& Jurisprudence, 1911.

BOBBIO, Norberto. Teoria dell'Ordinamento Giuridico. Torino: Giappichelli, 1960.

BONFANTE, Pietro. Famiglia e Successione. Torino: Unione Toporgracio: Editrice Torinese, 1926.

BRASIL. Lei $n^{\circ}$ 3.071, de 1 de janeiro de 1916, da República Federativa do Brasil. Brasília, DF. Disponível em: $\quad<$ http://www.planalto.gov. br/ccivil_03/Leis/L3071.htm>. Acesso em: 20 jan. 2012. - Lei $n^{\circ}$ 10.406, de 10 de janeiro de 2002, da República Federativa do Brasil. Brasília, DF. Disponível em: <http:// www.planalto.gov.br/ccivil_03/ LEIS/2002/L10406compilada. htm>. Acesso em: 20 jan. 2012.

COULANGES, Fustel de. A cidade antiga: estudos sobre o culto, o direito, as instituições da Grécia e de Roma. Tradução de Jean Melville. Martin Claret, 2001.

FRANÇA. Código Civil Francês. 107. ed. Paris: Dalloz, 2008.

GILSSEN, John. Introdução Histórica ao Direito. 2. ed. Lisboa: Fundação Calouste Gulbenkian, 1995.
GONÇALVES, Carlos Roberto. Direito Civil Brasileiro. V. VI. 5. ed. São Paulo: Saraiva, 2008.

HÉMARD, Joseph. Précis Élémentaire de Droit Civil. 2. ed. Paris: Librairie du Recueil Sirey, 1936.

ITÁLIA. Codice Civile. Milano: Egea, 2008.

JUSTINIANO, García Del Corral Ildefonso 1889. Cuerpo del Derecho Civil Romano. T. IV. Barcelona, 1889.

JUSTINIANUS, Flavius Petrus Sabbatius. Institutas. Tradução e notas de Edson Bini. Bauru: EDIPRO, 2001.

KASER, Max. Direito Privado Romano. Lisboa: Fundação Calouste Gulbenkian, 1999.

LEPOINT, Gabriel. La Famille das L'Ancien Droit. Paris: Éditions Domat Montchrestien, 1947.

MADALENO, Rolf. Regime de bens entre os cônjuges. Direito de Família e o novo Código Civil, Belo Horizonte: Del Rey, 2001.

MARTINS, Fabiane Parente Teixeira; BOIAGO JÚNIOR, José Wilson. Questões controvertidas sobre a mutabilidade do regime de bens para as causas ensejadoras da separação obrigatória. Revista $\mathrm{Na}$ cional de Direito e Jurisprudência, n. 94, ano 8, out. 2007.

MAZEAUD, Henri et Léon; MAZEAUD, Jean. Leçons de Droit 
Civil. Paris: Éditions Montchrestien, 1955.

MONTEIRO, Washington de Barros. Curso de direito civil. V. 2. Direito de família. Atualizado por Regina Beatriz Tavares da Silva. 37. ed. São Paulo: Saraiva, 2004.

NADER, Paulo. Curso de Direito Civil. Rio de Janeiro: Forense, 2006. NORONHA, Carlos Silveira. Conceito e fundamentos da família e sua evolução na ordem jurídica. Revista Forense, Rio de Janeiro, v. 326, abr. mai. jun. 1994.

PONTES DE MIRANDA, Francisco Cavalcanti. Tratado de Direito Privado. Tomo VIII, Rio de Janeiro: Borsoi, 1955.

PORTUGAL. Ordenações Afonsinas. Disponível em: <http://www1. ci.uc.pt/ihti/proj/afonsinas/14p76. htm>. Acesso em: 20 jan. 2010.

- Ordenações Manuelinas.

Disponível em: <http://www1. ci.uc.pt/ihti/proj/afonsinas/14p76. htm>. Acesso em: 20 jan. 2010.

. Ordenações Filipinas. Disponível em: <http://www.ci.uc. pt/ihti/proj/filipinas/14p832.gif $>$. Acesso em: 20 jan. 2010

Alvará de 23 de setembro de 1770. Disponível em: <http:// www.ci.uc.pt/ihti/proj/filipinas/ 14pa1062.htm>. Acesso em: 20 jan. 2010.
- Código Civil Português. Disponível em: <http://www. confap.pt/docs/codcivil.PDF $>$. Acesso em: 20 jan. 2010.

RODRIGUES, Sílvio. Direito civil: direito de família. 28. ed. rev. e atual. por Francisco José Cahali. São Paulo: Saraiva, 2006. V. 6.

ROMA. Código de Justiniano. Disponível em: <http://web. upmf-grenoble.fr/Haiti/Cours/ $\mathrm{Ak} />$. Acesso em: 20 jan. 2010 ROMANO, Santi. L'ordinamento giuridico. Firenze: Sansoni, 1951. ROSA, Conrado Paulino da. Desatando Nós e Criando Laços. Belo Horizonte: Del Rey, 2012. SANTOS, Eduardo dos. Direito da Família. Lisboa: Almedina, 1985. SAVATIER, René. Cours de Droit Civil. 2. ed., 1947.

TEDESCHI, Guido. Il Regime Patrimoniale della Famiglia. 3. ed. Torino: Unione Tipográfico Editrice Torinese, 1956.

VENOSA, Silvio de Salvo. Direito de Família. V. 6. São Paulo, Atlas, 2003.

ZOPPINI, Andrea. L'autonomia privata nel Diritto di Famiglia, sessant'anni dopo. Rivista di Diritto Civile. Padova: CEDAM Casa Editrice Dott. Antoni Milani, Ano XLVIII, Mar./Apr. 2002. 